\title{
Polyploidy and the petal transcriptome of Gossypium
}

\author{
Aditi Rambani ${ }^{\dagger}$, Justin T Page ${ }^{\dagger}$ and Joshua A Udall
}

\begin{abstract}
Background: Genes duplicated by polyploidy (homoeologs) may be differentially expressed in plant tissues. Recent research using DNA microarrays and RNAseq data have described a cacophony of complex expression patterns during development of cotton fibers, petals, and leaves. Because of its highly canalized development, petal tissue has been used as a model tissue for gene expression in cotton. Recent advances in cotton genome annotation and assembly now permit an enhanced analysis of duplicate gene deployment in petals from allopolyploid cotton.

Results: Homoeologous gene expression levels were quantified in diploid and tetraploid flower petals of Gossypium using the Gossypium raimondii genome sequence as a reference. In the polyploid, most homoeologous genes were expressed at equal levels, though a subset had an expression bias of $A_{T}$ and $D_{T}$ copies. The direction of gene expression bias was conserved in natural and recent polyploids of cotton. Conservation of direction of bias and additional comparisons between the diploids and tetraploids suggested different regulation mechanisms of gene expression. We described three phases in the evolution of cotton genomes that contribute to gene expression in the polyploid nucleus.

Conclusions: Compared to previous studies, a surprising level of expression homeostasis was observed in the expression patterns of polyploid genomes. Conserved expression bias in polyploid petals may have resulted from cis-acting modifications that occurred prior to polyploidization. Some duplicated genes were intriguing exceptions to general trends. Mechanisms of gene regulation for these and other genes in the cotton genome warrants further investigation.
\end{abstract}

Keywords: Cotton, Polyploid, Gene expression, Petal, Expression level dominance, Homoeo-SNP, Gene expression bias, Homoeolog

\section{Background}

The genus Gossypium currently consists of approximately 45 diploid and six polyploid species $[1,2]$. The six polyploid species of this genus formed between 1-2 million years ago $[3,4]$. While these polyploid species are currently geographically separated, their monophyletic origin makes this genus an ideal system to study the effects of polyploidization on gene expression. Two polyploid species, G. hirsutum and G. barbadense, produce spinnable fiber used by the textile industry and represent the majority of world-wide cotton production. An investigation of the effects of polyploidization on gene expression could further our understanding of

\footnotetext{
* Correspondence: jaudall@byu.edu

${ }^{\dagger}$ Equal contributors

Plant and Wildlife Science Department, Brigham Young University, Provo, UT 84602, USA
}

\section{Biomed Central}

the basis of superior cotton fiber qualities and fiber yields in tetraploid cotton cultivars.

Polyploidization causes a simultaneous duplication of all nuclear DNA, and some of the genomic consequences of polyploidization can be dramatic [5-7]. One consequence of polyploidization is unequal expression of homoeologous loci. This phenomenon was first described in cotton, for single duplicate gene pairs using Single-Strand Conformation Polymorphism (SSCP) $[1,2,8]$ and genome-wide using custom DNA microarrays $[3,4,9]$. Subsequent investigations found that expression biases between duplicate genes could be due to growth stage [10-13] or stress [14] and that the inter-genomic biases were reminiscent of monoallelic expression biases (i.e. inter-allelic) in diploid Homo sapiens [15-17]. Regardless of the growth stage, tissue, or stress, the degree of bias between duplicated gene pairs was distributed across a spectrum 
of different expression ratios including the 50:50 ratio of most homoeologous gene pairs $[12,18,19]$. Of the genes with biased expression in petal tissue, approximately $76 \%$ of homoeolog expression biases were immediately apparent after genomic merger, while the remaining $24 \%$ of homoeolog expression biases had been molded by evolutionary forces over time [20]. The expression level changes that accompanied polyploidization were considered two distinct phases of duplication gene evolution and have been reported in other natural and synthetic allopolyploid species [6,21-26].

Another consequence of polyploidization is expression level dominance. Expression level dominance has been characterized by the abundance of transcript rather than the transcript origin [4]. It was defined by comparing expression levels in Gossypium tetraploids to those in related diploids for a given gene. When the tetraploid gene expression level was statistically indistinguishable from one of the diploids, it was assumed that the diploid with the expression level matching that found in the polyploid was dominant. When many genes throughout the genome exhibited expression dominance, the generalized trend was considered expression level dominance of the genome if one of the two genomes was more frequently dominant than the other genome in the tetraploid nucleus. An expression dominance of one of the two genomes was found in leaf $[19,27]$ and petal $[18,20]$ tissue of interspecific hybrids and natural Gossypium polyploids. Expression level dominance has also been observed in other polyploid species such as Coffea [28], Spartina [6] and wheat [7]. Molecular factors contributing to expression level dominance are still unclear, but the cis- and trans-interactions of the regulatory machinery in the two distinct genomes are one explanation [29]. External factors could also play a role since temperature was shown to influence the magnitude and direction of expression level dominance in Coffea species [28]. Differential epigenetic regulation is another possible explanation.

Previously, the transcript contributions of the two coresident cotton genomes were quantified by custom microarrays $[9,10,18]$ or with RNA-seq and EST assemblies [19]. However, a more accurate assessment of transcriptome composition is possible through RNA-seq technology because gene expression measurement by RNA-seq is not influenced by probe specificity, ascertainment bias of a template sequence, and cross-hybridization [30,31]. Here, we used RNA-seq and the annotated genes of $G$. raimondii to measure gene expression in several polyploid accessions of cotton within its phylogenetic framework.

\section{Methods}

Plant material

Six accessions were used in our study: G. arboreum $\left(2 \times=2 \mathrm{n}=26, \mathrm{~A}_{2}\right), \quad$ G. raimondii $\left(2 \mathrm{x}=2 \mathrm{n}=26, \mathrm{D}_{5}\right)$,
G. tomentosum $\left(4 \mathrm{x}=2 \mathrm{n}=52, \mathrm{AD}_{3}\right), \mathrm{G}$. hirsutum cv. Acala Maxxa $\left(4 x=2 n=52, A_{1}\right.$; referred to as Maxxa), G. hirsutum cv. T×2094 (referred to as Tx; $4 \times=2 n=52$, $\left.\mathrm{AD}_{1}\right)$ and a sterile diploid $\mathrm{F}_{1}$-hybrid between $\mathrm{A}_{2}$ and $\mathrm{D}_{5}$ $\left(1 \times=1 n=26 ; F_{1}\right)$ (Table 1$)$. The diploid $F_{1}$-hybrid was created by a hand pollination between reduced gametes of diploids G. arboreum $\left(\mathrm{A}_{2}\right)$ and $G$. raimondii $\left(\mathrm{D}_{5}\right)$, and its somatic cells only contain 13 chromosomes from each extant diploid genome (Table 1).

Petal tissue was collected from plants growing under controlled greenhouse conditions at the Pohl Conservatory, Iowa State University, USA. Tissue was harvested at the time of full petal expansion after dawn but before pollination. Taking one flower from three different plants made three biological replicates for experiments. Harvested tissue was flash frozen in liquid nitrogen and stored at $-80^{\circ} \mathrm{C}$ until RNA and DNA extraction.

\section{RNA extractions, RNA-Seq libraries and sequencing}

RNA samples were extracted from the three replicates using a modified hot borate method [32]. RNA samples were quantified using Ribogreen (Invitrogen Inc., Grand Island, NY) and their quality was evaluated on an Agilent Bioanalyzer (Agilent Technologies, Santa Clara, CA). As described by Illumina, cDNA was sheared by sonication to a 200-400 bp fragment size (Covaris Inc., Woburn, MA). RNA-seq libraries were prepared according to the Illumina TruSeq RNA library prep kit protocol and sequenced on an Illumina HiSeq using v.2 chemistry at the Huntsman Cancer Center, SLC, UT. The sequencing reads are available at the NCBI Sequence Read Archive under Study: SRP028270 and Experiment: SRX328344.

\section{Data analysis \\ Quality filtering and quantitative assessment of RNA Seq reads}

Reads were filtered and trimmed using sickle with a phred quality threshold of 20 (https://github.com/najoshi/sickle). Diploid and tetraploid sequencing reads were individually mapped using GSNAP [33] to the diploid genome reference of G. raimondii [34]. Tetraploid reads were categorized in two groups, $\mathrm{A}_{\mathrm{T}}$ and $\mathrm{D}_{\mathrm{T}}$, using PolyCat with an index of 24 $\mathrm{M}$ homoeo-SNPs identified between several $\mathrm{A}_{1} / \mathrm{A}_{2}$ and $D_{5}$ accessions [35,36] (Table 2). We assessed the transcript abundance for each gene and converted raw read counts to RPKM (reads per kilobase per million mapped reads).

\section{Petal transcriptome analysis}

Universal Probability of expression Codes (UPC) uses a mixed-model approach to quantify the probability of gene expression in a sample [37]. UPC determined which genes were actively expressed in the petal tissue for each accession. Active genes in all the accessions were called 'commonly expressed genes' and they were 
Table 1 List of plant materials used in this study

\begin{tabular}{lccccrr}
\hline Species name & Genome designation & Accession & Ploidy level & Location & Raw reads & Trimmed reads \\
\hline G. arboreum & $\mathrm{A}_{2}$ & AKA8401 & Diploid & Africa & $46,155,539$ & $42,047,506$ \\
G. raimondii & $\mathrm{D}_{5}$ & $\mathrm{GN33}$ & Diploid & South America & $43,715,468$ & $39,974,015$ \\
G. hirsutum & $\mathrm{AD}_{1}$ & Maxxa & Tetraploid & Mexico & $42,719,425$ & $36,756,492$ \\
G. hirsutum & $\mathrm{AD}_{1}$ & T×2094 & Tetraploid & Yucatan Peninsula & $47,212,060$ & $43,247,980$ \\
G. tomentosum & $\mathrm{AD}_{3}$ & WT936 & Tetraploid & Hawaii & $41,893,620$ & $38,350,345$ \\
G. arboreum X G. raimondii & $\mathrm{A}_{2} \times \mathrm{D}_{5}$ & Unnamed & F F-haploid & NA & $43,247,980$ & $40,655,468$ \\
\hline
\end{tabular}

used to generate GO annotations for the petal transcriptome through Blast2GO [38]. BLASTX was performed on the Fulton Super Computer at BYU. Blast2GO visual tools were employed to build pie charts depicting gene ontology. Utilizing GO annotations and Enzyme Codes (EC) the KEGG IDs were assigned to each gene and the transcript abundance was calculated for KEGG pathways [39].

\section{Differential expression analysis}

EdgeR was used to normalize expression data and perform differential expression analysis [40]. Two factors were used as explanatory variables in model design matrix: 'accession' with four levels (diploid $\mathrm{F}_{1}$-hybrid, G. tomentosum, G. hirsutum Tx2094, G. hirsutum Maxxa) and 'genome' with two levels (A-genome or D-genome). A single, nested interaction design was used to determine genes significantly differentially expressed between accessions. A separate, simple single factor experiment with 8 levels was used to detect genes differentially expressed between two genomes for each accession. EdgeR performs exact test for the negative binomial distribution coefficients to provide p-values and false discovery rates (q-values) for all the genes. Genes with $<0.05$ FDR were considered differentially expressed.

\section{Expression phylogeny}

A phylogeny based on expression levels of the genes from all the accessions was built using the neighborjoining algorithm, with sum of squared differences for all genes between accessions within a distance matrix. We built another phylogeny using the neighbor-joining algorithm based on the difference between the two homoeologous gene expression levels.

\section{Expression level dominance analysis}

To analyze expression level dominance, every gene of each polyploid accession was separately analyzed and characterized according to the relationships between the RPKM values of the different genomes. Genes without expression in petals as determined by UPC were excluded from analysis. Each gene was categorized after comparison of $A_{2}$ and $D_{5}$ expression to the total expression of the polyploid. A matrix was constructed with the number of genes from the two comparisons and these numbers were used to calculate the total number of genes in each category of expression level dominance.

\section{Results}

\section{Gene expression in cotton petals}

A total of $50 \mathrm{bp}$, single-ended RNA-seq reads were generated from three replicates of each accession (Table 1). Maxxa and G. tomentosum had the most RNA-seq reads (> $40 \mathrm{M}$ each) and diploid $\mathrm{D}_{5}$ had the fewest RNA-seq reads $(\sim 37 \mathrm{M})$. Each of these reads was mapped (or aligned) to the 13 large pseudo-molecules of the D-genome reference sequence (v. 2.2.1, [34]) containing an initial set of gene annotations. Not all the reads mapped to the reference genome sequence. Perhaps this is

Table 2 Number of reads (Millions) that were categorized from reference mapping RNA-seq reads

\begin{tabular}{|c|c|c|c|c|c|c|}
\hline Accessions & A- Reads & D- Reads & X Reads & N Reads & Mapped total & Mapped\% \\
\hline G. arboreum & 16.5 & 0.1 & 0 & 14 & 30.8 & $73.30 \%$ \\
\hline G. raimondii & 0 & 17.1 & 0 & 16.5 & 33.9 & $84.70 \%$ \\
\hline Diploid $F_{1}$-Hybrid & 8 & 8.4 & 0.1 & 15.1 & 32 & $78.80 \%$ \\
\hline G. hirsutum Maxxa & 7 & 6.7 & 1.2 & 13.5 & 28.6 & $77.70 \%$ \\
\hline G. hirsutum Tx2094 & 8 & 7.7 & 1.4 & 15.7 & 33.1 & $76.60 \%$ \\
\hline G. tomentosum & 7.3 & 6.9 & 1.3 & 14.2 & 29.8 & $77.60 \%$ \\
\hline Total & 46.8 & 46.9 & 4.1 & 88.9 & 188.2 & $78.10 \%$ \\
\hline
\end{tabular}

A- and D-reads were categorized as belonging to the A- and D-genomes. X-reads exhibited a mixed signal, with evidence for both genomes. N-reads did not overlap a known homoeo-SNP and could not be categorized. 
because either the initial draft of the D-genome reference did not have all of the genes annotated, or because transcripts mapped to genomic regions outside of annotated genes, or because some of the genes were not assembled to the 13 large pseudo-molecules. Of the annotated genes in the reference pseudo-molecules, $80 \%$ had at least one mapped read from the petal tissue.

Approximately $25 \%$ of the mapped reads were assigned to each genome $\left(A_{T}\right.$ and $\left.D_{T}\right)$. If the mapped reads overlapped a homoeo-SNP position (SNPs between the A- and $\mathrm{D}$-genomes), they were categorized as belonging to one of the two genomes or as a chimeric read because it had $\mathrm{A}$ - and D-genome nucleotides at different loci in close proximity (A-reads, D-reads, and X-reads, respectively; [35]). If a read did not overlap a homoeo-SNP position, the read was unable to be categorized as originating from either the $A_{T^{-}}$or $D_{T^{-}}$genome ( $\mathrm{N}$ reads) (Table 2). The number of uncategorized reads was not unexpected given the limited divergence between the $\mathrm{A}_{\mathrm{T}^{-}}$and $\mathrm{D}_{\mathrm{T}^{-}}$-genome in coding sequences [41].

Depending on the accession, approximately $45-50 \%$ of the genome is expressed in petals based on the UPC analysis. This total is lower than the number of cotton genes found to be expressed in fiber tissue $(75-90 \%)$ at any developmental stages $[12,19]$. This could be due to the higher level of canalization of petal tissue compared to fibers. Of 37,223 genes annotated in the reference Dgenome, 11,469 genes were commonly expressed in petals of all polyploid accessions as determined by UPC (Figure 1, Table 3). This number of commonly expressed genes represented approximately $80 \%$ of the expressed genes in each accession.

Using Blast2GO, we assigned GO IDs to the common genes based on their RefSeq Blast hits and categorized them into three separate gene ontologies according to

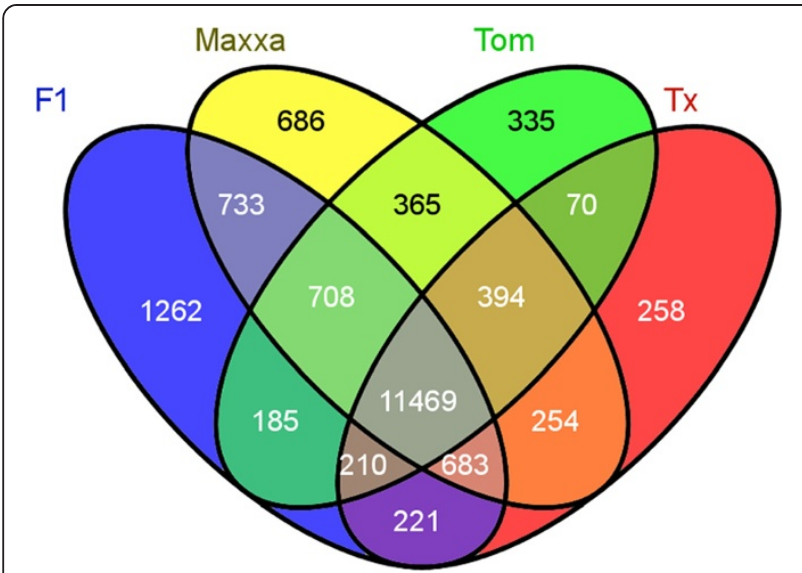

Figure 1 Venn diagram for genes expressed in all the accessions above the background expression level. their putative function [38] (Additional file 1: Figure S1). The cellular component (CC) ontology had the highest number of assigned GOIDs (88\%) followed by the biological process (BP) ontology (17\%) and molecular process (MP) ontology (9\%). The most abundant GO terms of CC were cytoplasm related (cytoplasm (28\%) and cytoplasmic part (27\%, Additional file 2: Figure S2). Cellular protein metabolic processes (31\%) and kinase activity (41\%) were the most plentiful GO terms for the BP and MP ontologies, respectively. Similar distributions among categories have also been reported from the petal tissue of other species, like Dianthus [42] and Safflower [43]. Enzyme-coding genes were identified and their role in KEGG enzymatic pathways was determined. A total of 4,565 genes were assigned an enzyme code ID corresponding to 654 different enzymes (i.e. many genes were members of large gene families). These 654 enzymes were found to be part of 93 different enzymatic pathways in petal tissue. The enzymatic pathways can be divided into four general categories: Metabolic pathways, Biosynthetic pathways, Degradation pathways and signaling pathways (Additional file 2: Figure S2). Transcript abundance of genes involved in metabolic pathways like starch and amino sugar metabolism was highest in petal tissue compared to other enzymatic pathways. Amongst biosynthetic pathways, biosynthesis of amino acids and flavonoids were most abundant whereas other processes like wax and pigment synthesis had smaller representation.

\section{Differential gene expression between accessions}

Phylogenetic relationships of Gossypium species have been well characterized using thousands of genes [41]. It is also possible to ascertain whether variances of gene expression levels follow these evolutionary relationships [18]. Our analysis of Gossypium gene expression values resulted in branching patterns similar to that created by previous microarray gene expression levels and to the accepted genetic relationships between species $[1,44]$. The single expression, phylogenetic tree had two main branches containing the $\mathrm{A}_{\mathrm{T}^{-}}$and $\mathrm{D}_{\mathrm{T}^{-}}$-genomes, (Figure 2). As expected, the respective genomes of the two G. hirsutum accessions, Maxxa and Tx2094, were closely related and clustered together. Using contrasts within EdgeR, differential expression analysis showed that 692 genes were differentially expressed between these two accessions of G. hirsutum regardless of the transcript origin. There were 1,394 genes differentially expressed between the two accessions of $G$. hirsutum and $G$. tomentosum. The diploid $F_{1}$-hybrid was found to have total expression levels more closely resembling the diploid species than the natural polyploids as might be expected based on its recent origin. The diploid $F_{1}$-hybrid had 2,671 genes differentially expressed between it and the natural polyploids. 
Table 3 The number of genes expressed in each Gossypium accession, the total number shared by every accession, and the number of genes found to have unequal transcript contribution of both genomes $\left(A_{T}\right.$ and $\left.D_{T}\right)$ to the transcript pool (genome bias)

\begin{tabular}{|c|c|c|c|c|c|c|c|}
\hline Accession & Total expressed & $\%$ expressed & Total biased & $\%$ biased & $A_{T}$ bias & $\mathrm{D}_{\mathrm{T}}$ bias & Bias ratio \\
\hline Diploid $F_{1}$-hybrid & 15,471 & 41.6 & 2,060 & 13.3 & 1,027 & 1,033 & 0.99 \\
\hline G. tomentosum & 13,736 & 36.9 & 3,706 & 27.0 & 1,891 & 1,815 & 1.04 \\
\hline G. hirsutum Maxxa & 15,292 & 41.0 & 3,146 & 20.6 & 1,556 & 1,590 & 0.98 \\
\hline G. hirsutum Tx2094 & 13,559 & 35.4 & 2,686 & 19.8 & 1,350 & 1,336 & 1.01 \\
\hline Commonly expressed & 11,469 & & $478^{*}$ & & $246^{*}$ & $202^{*}$ & \\
\hline
\end{tabular}

*Genes expressed in each of the accessions (Figure 6).

\section{Differential gene expression between homoeologs}

The two co-resident genomes of polyploid nuclei did not always contribute equally to the transcript pool. Unequal contribution by the $\mathrm{A}_{\mathrm{T}^{-}}$and $\mathrm{D}_{\mathrm{T}^{-} \text {genome homoeologs }}$ to the cotton transcript pool of any single gene (on the D-genome reference sequence) is referred to as 'genome bias' $[4,9,18,19,45]$. A comparison of the number of biased genes between accessions indicated that the large majority of genes did not have a genome bias (i.e. bias ratio of $\mathrm{A}_{\mathrm{T}}$ / $D_{T}$ where $A_{T}>D_{T}$ or vice versa) when the genes with $99 \%$ UPC expression likelihood were considered. Approximately $20 \%$ of genes expressed in petals had a significant bias towards the $\mathrm{A}_{\mathrm{T}^{-}}$or $\mathrm{D}_{\mathrm{T}}$-genome (Table 3 ). Though it wasn't significantly different, G. tomentosum had the highest number of biased genes, followed by Maxxa, then Tx2094, among the natural tetraploids. This ranking was similar to a previous study of petal tissue that also found a higher number of biased genes in G. tomentosum than in G. hirsutum or the diploid $F_{1}$-hybrid [18]. We included G. tomentosum in this study because it had a greater number of homoeologous genes with large expression biases (i.e. a broader distribution of $\mathrm{A} / \mathrm{D}$ expression ratios) than other polyploids. However, we found only subtle differences in the distribution ratios of gene expression among any of the accessions using RNA-seq (Additional file 3: Figure S3). The most notable difference of the distributions was that the diploid $F_{1}$-hybrid had a smaller proportion of expressed genes with a detectable expression bias.

Many commonly expressed genes with homoeologous expression bias were found in more than one accession (Figure 3A). For example, 2,060 genes were identified with an expression bias in the petal tissue of the diploid $F_{1}$-hybrid; of these, 1,292 of these genes were expressed in all accessions. A small set of homoeologous gene pairs (478, 4\%

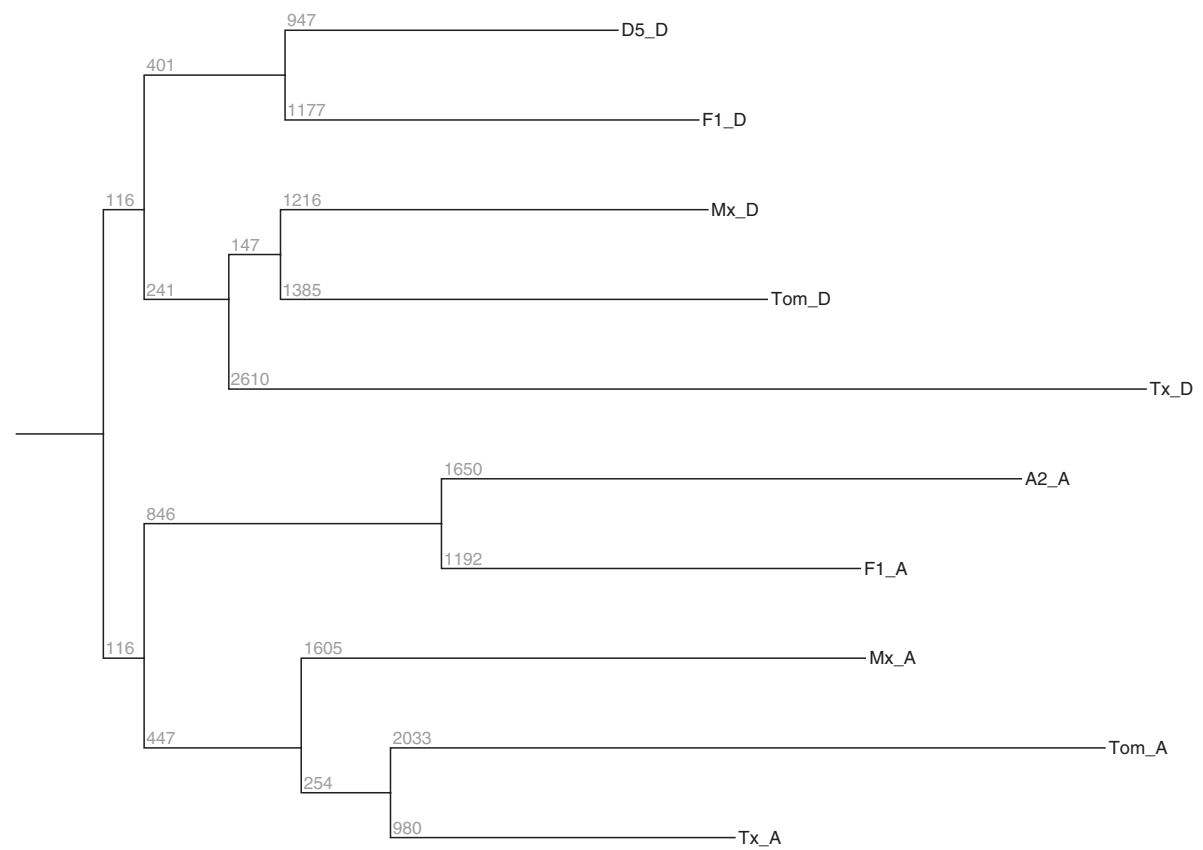

Figure 2 Phylogenetic tree (neighbor joining in PHYLIP) based on gene expression levels of commonly expressed genes from all the accessions where $\mathrm{F} 1=$ diploid $\mathrm{F}_{1}$-hybrid; $\mathrm{Mx}=G$. hirsutum var Maxxa; $\mathrm{Tx}=G$. hirsutum var $\mathrm{T} \times 2094 ; \mathrm{Tom}=G$. tomentosum, $-A=A_{T}$ and_D $=D_{T}$. 


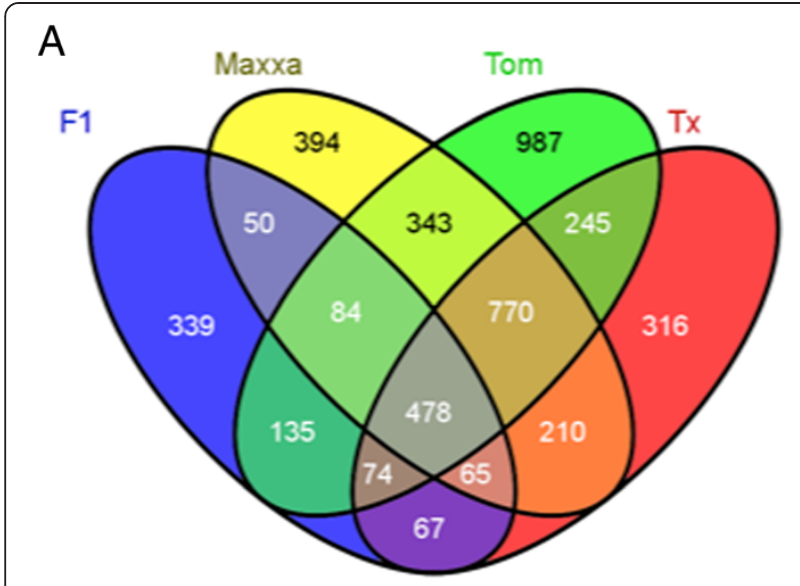

B

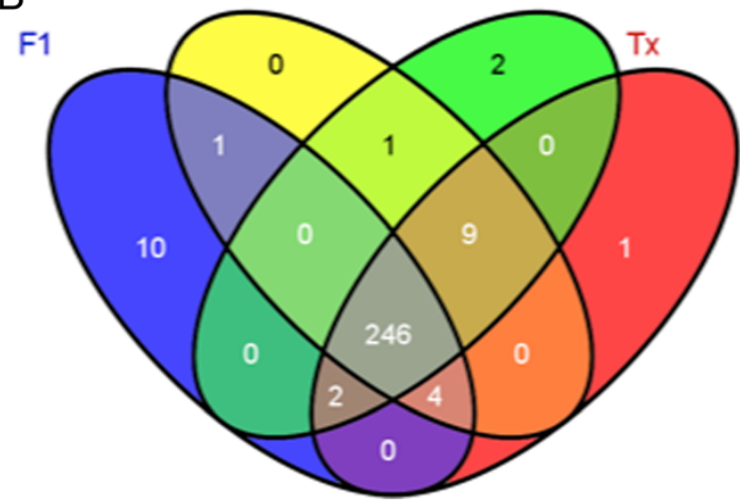

Figure 3 Venn diagram for number of genes showing homoeologous expression bias in each accession. A) Total numbers of biased genes in each accession corresponding to the numbers in Table 3. B) Of the 478 genes commonly biased in either direction in every accession, only the numbers displayed were biased in the $A_{T}$ direction.

of commonly expressed genes) was found to have an expression bias in each polyploid petal transcriptome. When the degree of bias of these genes was compared to the remaining biased gene pairs for each accession, these 478 biased pairs had a significantly larger degree of bias than the remaining gene pairs (between $1.3-1.6$ fold greater on average; $\mathrm{p}<0.001$ ). For example, the degree of bias for the 478 'conserved' genes was significantly higher than the degree of bias of the remaining 814 genes in the diploid $\mathrm{F}_{1}$-hybrid.

The direction of bias for these 478 gene pairs was conserved for most petal transcriptomes with a few exceptions. Of the 478 gene pairs, 246 were consistently biased in the $\mathrm{A}_{\mathrm{T}}$ direction (Figure 3B) and 202 were consistently biased in the $\mathrm{D}_{\mathrm{T}}$ direction. These 448 gene pairs were located on all thirteen chromosomes of the D-genome reference. Since we found a significant correlation $(\mathrm{p}<0.005)$ between the number of total genes/chromosome and number of biased genes/chromosome, the homoeologous gene expression bias was probably not related to their chromosomal location. Interestingly, 19 gene pairs in the diploid $\mathrm{F}_{1}$-hybrid had consistent, yet contrary biases compared to the natural polyploids (e.g. a gene pair within the diploid $\mathrm{F}_{1}$-hybrid had an $\mathrm{A}_{\mathrm{T}}$-bias, but a $\mathrm{D}_{\mathrm{T}}$-bias was detected in all of the other three natural polyploids). In addition, each of the polyploids had a unique set of a small number of gene pairs with a contrarian directional bias than the remaining accessions (6 genes in G. tomentosum, 2 genes in Maxxa, and 1 gene in Tx2094).

Zooming out to reconsider accession totals of biased genes, 339 genes were biased in the diploid $F_{1}$-hybrid but not the natural polyploids, while 770 genes were biased in the natural polyploids but not the hybrid (Figure 3A). The expression bias of these 1,009 genes $(339+770)$ was found to be different between the diploid $F_{1}$-hybrid and the natural polyploids. Further examination of the 770 homoeologous gene pairs with conserved expression bias in the natural polyploids found that the direction of expression bias (i.e. $\mathrm{A}_{\mathrm{T}}>\mathrm{D}_{\mathrm{T}}$ or $\mathrm{D}_{\mathrm{T}}<\mathrm{A}_{\mathrm{T}}$ ) was conserved for all but 1-2 pairs of genes (depending on which two natural polyploids were compared). This conserved direction of homoeologous bias suggested a difference in cis-regulation of gene expression between genomes. Inspection of all of the other biases shared between two or more accessions found strong, consistent directions of homoeologous expression bias suggesting that the bias has roots in the independent evolution of the two progenitor species prior to reuniting within the common tetraploid nucleus.

The degree of bias (i.e. expression level differences of $A_{T}-D_{T}$ ) between $A_{T}$ and $D_{T}$ homoeologous gene copies for each of the commonly expressed genes were also visualized within the phylogenetic framework (Figure 4). The same relative tree topology between the accessions was observed in the gene expression tree and phylogenetic tree. The diploid $F_{1}$-hybrid was relatively distant from natural tetraploids in the phylogeny and it had the least number of biased genes.

One explanation of biased gene expression could be the distance of a gene to the nearest transposable element. In other words, gene proximity to a TE quantitatively reduces the amount of gene expression due to heterchromomatic effects. For example, the greaterthan-average A-genome bias of a subset of genes might be explained by greater distance between those genes and the nearest TE than the remainder of genes in the genome. In our data, TE proximity was only statistically associated with gene expression bias in Tx2094 ( $p=0.04$, Figure 5).

\section{Differential gene expression between the polyploids and diploids}

Considering expression patterns for duplicated genes in a polyploid, relative to their orthologs in related diploids, 


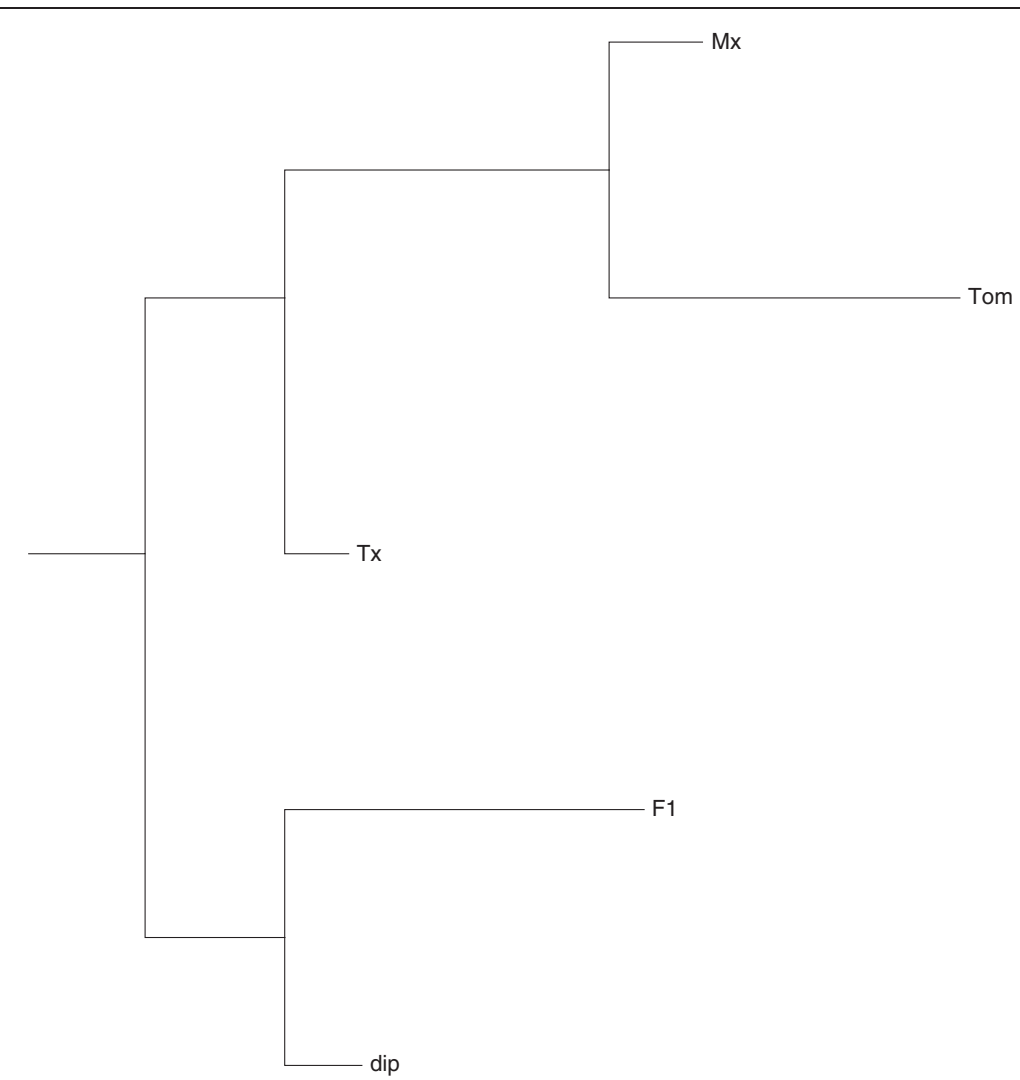

Figure $4 \mathrm{~A}$ phylogenetic tree based on the amount of expression divergence between homoeologous gene pairs $\left(F 1=\right.$ diploid $F_{1-}$ hybrid; Mx = G. hirsutum var Maxxa; Tx = G. hirsutum var TX2094; Tom = G. tomentosum).

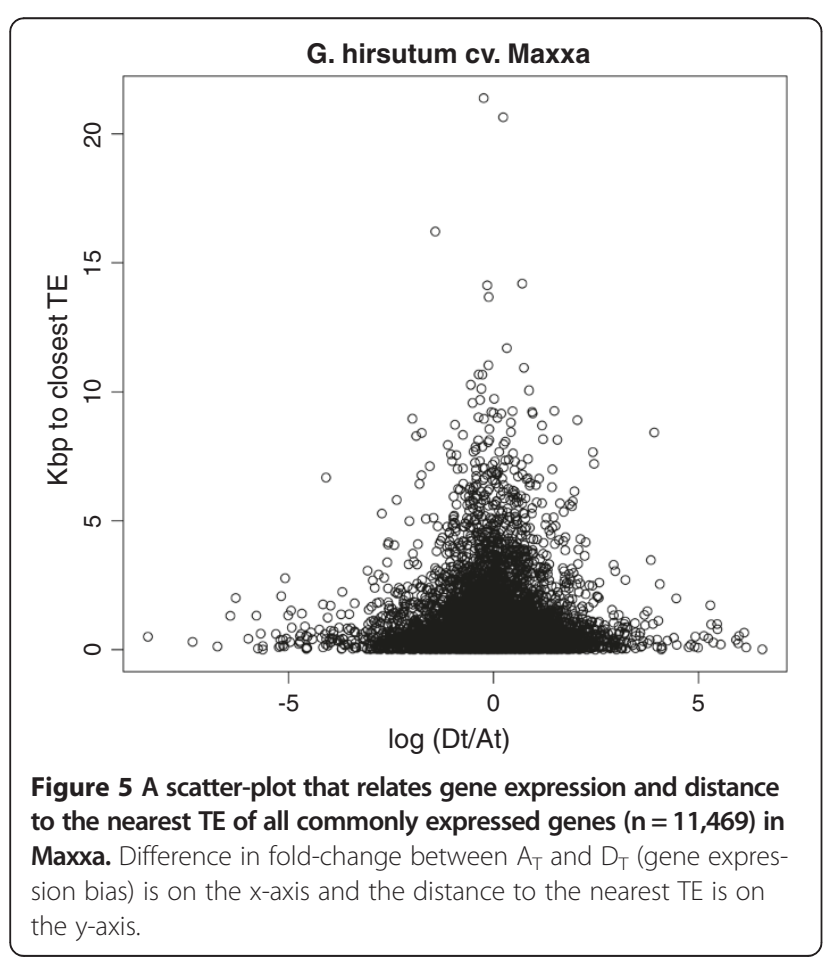

twelve possible categories have been described, where each category corresponds to a combination of relative equalities or inequalities between two diploids and between the total expression in the tetraploid $[18,19,27]$. The expression level profile of each gene can be placed in one of these categories and their relative abundance has been used to determine expression level dominance (ELD, Figure 6, $[4,18,19])$. In this context, additive expression is when the tetraploid expression level is approximately the average of the diploid expression levels. Transgressive expression (upward or downward) refers to expression categories where the tetraploid expression is either higher or lower than that in both diploid parents. Expression level dominance categories are those in which the expression level in the tetraploid matches the expression level in one of the two diploids, whether expression in that diploid is higher or lower than in the other diploid (II, IV, IX, XI, Figure 6; [4]). In general, the 3 natural allotetraploids (Maxxa, Tx2094, and G. tomentosum) exhibited a consistent expression pattern (i.e., approximately equal number of genes in equivalent categories). The diploid $\mathrm{F}_{1}$-hybrid frequently differed from the natural polyploids in gene expression levels and the categories of expression level dominance.

Counts of duplicated genes from this RNA-seq study were placed into the 12 expression levels categories and 


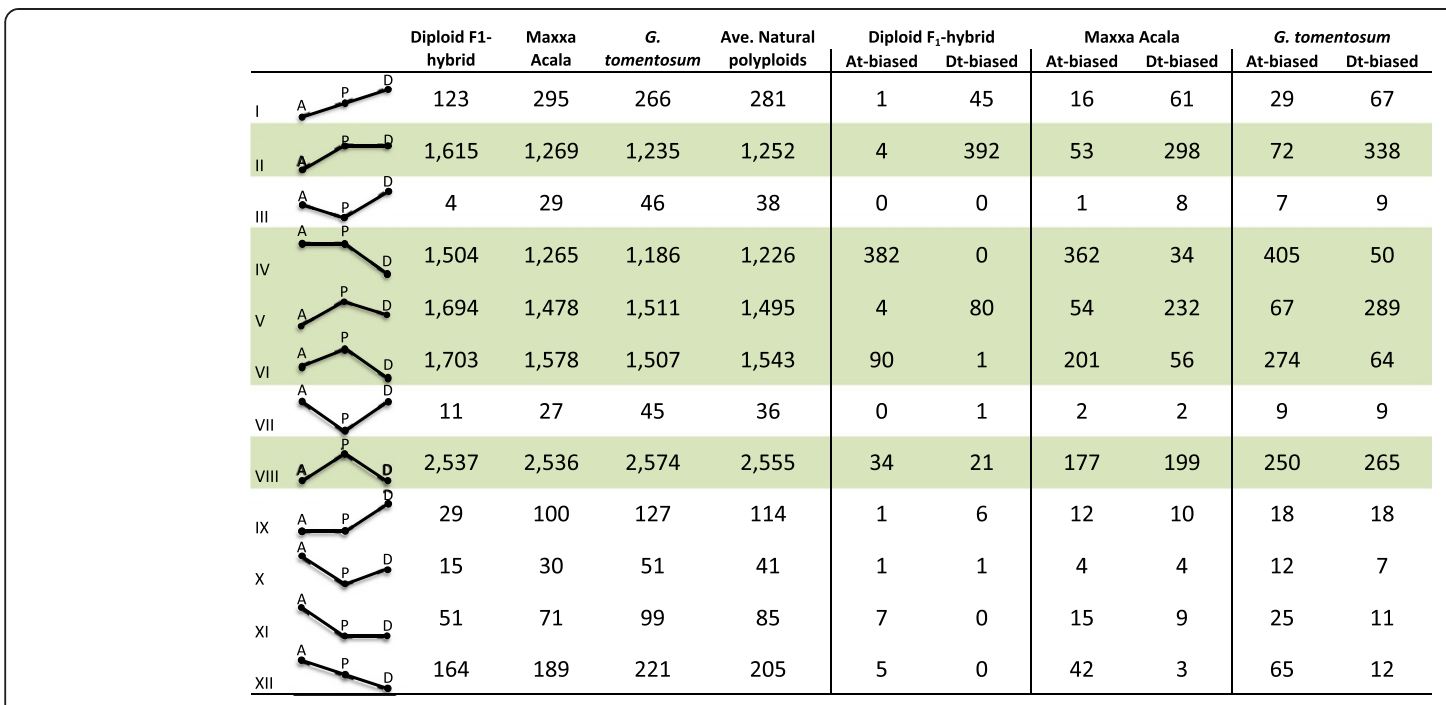

Figure 6 Number of genes in 12 categories listed in first column where 'A' = expression from A genome, ' $D$ ' = expression level from $D$ genome, and the ' $\mathbf{P}$ ' = expression level from polyploid. The position of letters $A, D$ and $P$ indicate the level of expression relative to the other. Rows shaded green indicate 'high-level expression' of the polyploid compared to the diploids.

compared to the previously reported microarray results of petal transcriptomes (Additional file 4: Figure S4, [18]). Previously, a modest level D-genome ELD was found as a ratio between categories (Categories II and XI/Categories IV and IX). In our RNA-seq results, we did not find a discernable level expression level dominance because the ELD ratios were very close to $1(0.92,1.02$, and 0.98 in the diploid $\mathrm{F}_{1}$-hybrid, Maxxa, and G. tomentosum, respectively). This disagreement between the microarray and RNA-seq results could have been due to an artifact of microarray probe design where more EST templates were available for the D-genome than the A-genome (i.e. floral ESTs were only obtained from the D-genome [46]). In addition, our use of SCAN UPC expression likelihoods reduced the amount of transcriptional noise by filtering the low-level expressed genes from the analysis (note the smaller total number of genes in each treatment, Additional file 4: Figure S4).

We found that the polyploid categories II and IV (greater expression of transcripts from both polyploid $\mathrm{A}_{\mathrm{T}^{-}}$and $\mathrm{D}_{\mathrm{T}^{-}}$genomes compared to diploids) are $\sim 10$-fold more abundant than categories IX and XI (less expression of transcripts from both polyploid $\mathrm{A}_{\mathrm{T}^{-}}$and $\mathrm{D}_{\mathrm{T}^{-}}$-genomes compared to diploids; Figure 6). All categories where polyploid gene expression level was expressed as high (or higher) as the diploid with the highest expression level had many genes (generally $>1,000$; categories II, IV, V, VI, and VIII). All categories where polyploid gene expression level was expressed as low (or lower) as the diploid with the lowest expression level had very few genes (generally $<$ 100; Categories III, VII, IX, X, and XI).

Because we could discern the $\mathrm{A}_{\mathrm{T}}$ and $\mathrm{D}_{\mathrm{T}}$ transcripts in our RNA-seq data, we were curious if the general trend of increased expression in the polyploid was due to an increase of transcription levels in a single genome or both genomes (Figure 6). Thus, we considered genes that had a significant expression bias within each of the 12 expression categories. For example, 1,504 genes exhibited expression level dominance of the $\mathrm{A}_{\mathrm{T}^{-}}$genome in the diploid $\mathrm{F}_{1}$-hybrid. Of those, $382 \mathrm{~A}_{\mathrm{T}}-\mathrm{D}_{\mathrm{T}}$ gene pairs contained homoeo-SNPs and had significant expression bias based on read counts of each homoeolog. All 382 of these gene pairs had a $\mathrm{A}_{\mathrm{T}}$-genome bias and 0 genes had

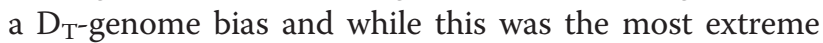
difference, it represented a general trend within the expression categories. Generally, the direction of expression level dominance in all 'increased expression' categories (Categories II, IV, V, and VI) coincided with the RNA-seq read composition of genes with significant homoeolog expression bias. Perhaps, this also indicated cis-acting regulation of genes where a higher expression of one of the two diploid genomes was conserved in the polyploid nucleus and potential overexpression was controlled by and at the same levels as in the diploids.

Interestingly, category VIII is described as exceptional or transgressive expression in the polyploid $\left(A=D<A_{T} D_{T}\right)$. It had equivalent contributions from each genome. In contrast to other categories, more genes were placed in this category on a percentage basis by our RNA-seq analysis than by the previous microarray experiment. There were also many fewer of these genes in the diploid $F_{1}$-hybrid than in the natural polyploids. Perhaps this transgressive expression represent a different type of 'additive' gene expression where each diploid contributes an additive amount of transcript (such that two copies in the nucleus results in twice as much gene product), except that these 
loci have not individually evolved a mechanism for feedback control of expression. Such an interpretation would agree with a form of pseudo-overdominance (i.e. heterosis) between genomes and may have been due to complementary combinations of cis- and trans-acting factors resulting in more expression together than either genome alone.

\section{A simplified approach to comparisons of gene expression} We generated a new perspective of gene expression in polyploid cotton by cross-listing two separate gene lists. The first list consisted of the genes that were differentially expressed between the diploids, $A_{2}$ and $D_{5}$, and the second list consisted of the genes that had expression bias in each hybrid or polyploid. For this perspective, assume that the two diploid genomes actually contain the ancestral genomes of the extant polyploids and that the diploid $\mathrm{F}_{1}$-hybrid is simply an intermediate step in their evolution. Four groupings of genes are useful for this consideration: exhibiting no differential expression in diploids or polyploids, differential expression in diploids only, differential expression in polyploids only, or differential expression in both diploids and polyploids (Table 4). It was uncommon for genes that were not differentially expressed in the diploids to develop differential expression in the polyploids (113/6,358 in F1, average $943 / 6,358$ in the natural polyploids). It was more likely for a differentially expressed gene in the diploid to become equally expressed in the polyploid than it was to stay differentially expressed (3,932 vs. 1,179 in diploid $F_{1}$-hybrid, 3,476 vs. 1,635 in the natural polyploids). In genes that were differentially expressed in both diploids and polyploids, it was rare for the direction of bias to change from one direction in the diploids to the opposite direction in the polyploid (1\% in diploid $\mathrm{F}_{1}$-hybrid, $16 \%$ in the natural polyploids). Inspection of $1,000 \mathrm{bp}$ upstream of the annotated genes did not reveal any significant differences in the number of SNPs between these two categories of genes (i.e. same expression levels between diploid and polyploid $v s$. different expression levels in diploids and polyploids, data not shown). Perhaps the causative differences of expression were further upstream [47] or caused by an indel. When changes in expression bias direction were identified, the bias appeared to slightly shift more towards the $\mathrm{A}_{\mathrm{T}}$-genome than the $\mathrm{D}_{\mathrm{T}}$-genome. Such a simplified perspective overlooks some complexities of cotton polyploid formation; however, it emphasizes the putative predominance of trans-acting regulation of gene expression in polyploid cotton if the 'different' categories are generally interpreted as cis-acting regulation.

In addition, we compared the average degree of bias detected in the diploid $\mathrm{F}_{1}$-hybrid to the average degree of bias detected in the natural polyploids. When there was a significant $\mathrm{D}_{\mathrm{T}}$ bias detected in the diploid $\mathrm{F}_{1}$-hybrid, there was also a significant difference in the amount of bias between the diploid $\mathrm{F}_{1}$-hybrid and the other polyploids. When there was a significant $\mathrm{A}_{\mathrm{T}}$ bias detected in the diploid $F_{1}$-hybrid, there was not a significant difference in the amount of bias between the $F_{1}$ and the other polyploids.

To complement that previous perspective, we also compared the expression of the $\mathrm{A}_{\mathrm{T}}$-genome to the diploid A-genome and the $\mathrm{D}_{\mathrm{T}}$-genome to the $\mathrm{D}$-genome (Table 5). The diploid $\mathrm{F}_{1}$-hybrid had fewer expression level differences with the diploids than did the natural polyploids

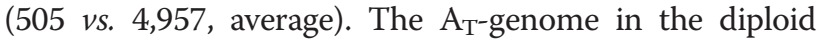
$\mathrm{F}_{1}$-hybrid had more expression level differences with the diploid A-genome than the $\mathrm{D}_{\mathrm{T}}$-genome did with the diploid D-genome (390 vs. 115), but the natural polyploids all had more expression level differences with the diploids in the $\mathrm{D}_{\mathrm{T}}$-genome than in the $\mathrm{A}_{\mathrm{T}}$-genome. When the polyploid had a different level of expression than its respective diploid, the $\mathrm{A}_{\mathrm{T}}$-genome expression levels were more frequently higher than the A-genome diploid expression levels and the $\mathrm{D}_{\mathrm{T}}$-expression levels were more frequently lower than the D-genome diploid expression levels.

\section{Discussion and conclusions}

Gossypium petal transcriptome

Cotton fiber tissue has been the main focus of many transcriptome studies of Gossypium species because of its economic importance [10-12,48,49]. In contrast, petal tissue is an excellent 'model' tissue for cotton gene expression because of its highly canalized development and limited interaction with the environment $[18,20]$. In one of the first applications of the G. raimondii reference

Table 4 Number of genes with or without differential expression in the diploids and polyploids (for example, 6,358 genes were equally expressed in the diploids; of those, 6,245 were also found to be equally expressed in the diploid $F_{1}$-hybrid and 113 were found to be differentially expressed in the diploid $F_{1}$-hybrid)

\begin{tabular}{|c|c|c|c|c|c|c|}
\hline \multirow{2}{*}{$\begin{array}{l}\text { Diploids } \\
\text { Polyploids }\end{array}$} & \multicolumn{2}{|c|}{ Equal } & \multicolumn{2}{|c|}{ Different } & \multicolumn{2}{|c|}{ Change } \\
\hline & Equal & Different & Equal & Different & $A->D$ & D- $>A$ \\
\hline Diploid $F_{1}$-hybrid & 6,245 & 113 & 3,932 & 1,179 & 2 & 8 \\
\hline G. tomentosum & 5,127 & 1,231 & 3,226 & 1,885 & 155 & 174 \\
\hline G. hirsutum maxxa & 5,509 & 849 & 3,566 & 1,545 & 102 & 125 \\
\hline G. hirsutum TX2094 & 5,609 & 749 & 3,635 & 1,476 & 97 & 127 \\
\hline
\end{tabular}


Table 5 Changes in gene expression from diploid to tetraploid genomes

\begin{tabular}{lcccr}
\hline & A $_{\mathbf{T}}$ up & A $_{\mathbf{T}}$ down & D $_{\mathbf{T}}$ up & D $_{\mathbf{T}}$ down \\
\hline Diploid $\mathbf{F}_{\mathbf{1}}$-hybrid & 235 & 155 & 47 & 68 \\
G. tomentosum & 1,396 & 1,294 & 1,624 & 1,719 \\
G. hirsutum maxxa & 1,080 & 813 & 1,396 & 1,396 \\
G. hirsutum TX2094 & 1,060 & 880 & 1,084 & 1,129 \\
\hline
\end{tabular}

" $A_{T}$ up" means that $A_{T}$ was more expressed than $A_{2}$, etc.

genome [34], the gene expression levels in petals were determined by mapping RNA-seq reads to the annotated genes. Only $36-42 \%$ of the Gossypium genome was expressed in the petal tissue of open flowers prior to pollination. This number was noticeably smaller than the number of genes expressed during the development of cotton fiber [10], but we only sampled one time point of petal development. Between $75 \%$ and $83 \%$ of the expressed genes were expressed in every accession (Table 3). While these commonly expressed genes had a 99\% probability of expression, they were not expressed at the same levels in the different accessions. Using gene expression as a metric [18], the expected phylogenetic relationships were clearly seen within a simple neighborjoining tree containing two major clades (A and D, Figure 4).

Distributing transcripts in GO categories developed a molecular snap shot of the petal tissue. The cellular component ontology that includes multi-subunit enzymes and other protein complexes was most abundant GO category (88\%). Petal cells undergo rapid elongation to reach full petal expansion stage. Actin cytoskeleton helps with cell elongation by transporting vesicles and organelles to the site of growth from cytoplasm. The cytoplasm (28\%) and cytoplasmic parts (27\%) were most represented under cellular component GO category. About $17 \%$ of transcripts fell under biological processes GO category and under this category cellular protein metabolic processes $(31 \%)$ were most prominent. Petal tissue is an energy sink tissue for plant reproduction where starch and sucrose are mobilized from photosynthetic organs and broken down to sugars that function as precursors to essential primary and secondary metabolites [50]. This was supported by the transcript abundance of different KEGG pathways. Many enzymes expressed in petal tissue were involved in starch and sucrose metabolism pathways.

In addition to a comprehensive assessment of gene expression in petals, the improvements in our analytical methodology resulted in three refinements of our understanding of the cotton transcriptome. First, both Yoo et al. [19] and this study found that expression bias is only found in a minority of genes. While previous studies used EST assemblies, we used an assembled genome reference and its corresponding gene annotations to determine gene expression resulting in more accurate numbers of expressed genes in a single tissue and the individual contributions of the distinct polyploid genomes.

Second, UPC was used to assign an expression probability to each gene. Genes with low expression levels have less accuracy and cause inflated comparisons of expression level differences due to overlapping standard deviations of expression (e.g., A is equal to P; D is equal to $\mathrm{P}$, but $\mathrm{A}$ is not equal to $\mathrm{D}$ ). Elimination of low-level expressed genes emphasized two clear trends of the polyploid transcriptome. The first trend was that we found negligible 'down-regulation' in the polyploid. When the low-level expressed genes (instead of a foldchange threshold) were eliminated, the frequency of categories of 'down-regulation' in the polyploid (III, IX, X, XI) were negligible compared to the frequency of 'up-regulation' categories (II, IV, V, VI). The second trend was that we found no ELD in the cotton petal transcriptome. Previously, a small D-genome ELD was found in petals, but it could be potentially explained by the origin of the microarray probes (Additional file 4: Figure S4). A small A-genome ELD in cotton leaves [19] could partially be explained by the difference of evolutionary distance between $A_{T}$ and $A_{2}$, and $D_{T}$ and $D_{5}$. Since $A_{T}$ and $A_{2}$ are $\sim 2 \times$ closer in sequence similarity than $\mathrm{D}_{\mathrm{T}}$ and $\mathrm{D}_{5}$, the $\mathrm{A}_{\mathrm{T}}$-genome reads of the polyploid are more likely to map as equally well (or equally poor) as the A-genome diploid than the D-genome sequences, particularly when an EST assembly of $A_{T}$ and $D_{T}$ is used a reference. This potential inherent bias is fully considered when SNP-tolerant mapping is used since SNP positions are masked during the read alignment resulting in normalized read mapping efficiencies. This study was the first study to use SNP-tolerant mapping in RNA-seq analysis of a polyploid transcriptome.

Third, when the polyploid had equal to the higher diploid parent (i.e. up-regulation categories II, IV, V, VI), it was previously found that the expression level of the polyploid was explained by an increased expression of the 'recessive' parent [19]. We found no evidence for a significant contribution from the 'recessive' parent. In fact, we observed an exceptional amount of expression stability between the diploid and polyploid petals. This paradoxical finding could be due to the differences between leaf and petal, or it could be due to the analytical refinements mentioned above. Further examination of additional RNA-seq dataset will contribute a greater understanding of ELD.

\section{Evolution of cotton gene expression}

Our results contribute to a growing understanding of the evolution of gene expression in cotton. Adams et al., [8] first reported expression bias in natural Gossypium polyploids. Since each gene and its corresponding cis-acting 
regulatory sequence(s) of the diploid A- and D-genomes can be traced to a common ancestry 5-10 mya [1], the cause of differential expression between homoeologs remained a mystery. Using microarray technology, homoeologous expression biases were observed in petal tissues from five Gossypium polyploids and a diploid $\mathrm{F}_{1}$-hybrid $[18,20]$. These previous observations suggested two phases or modes for the evolution of cotton gene expression during polyploidization. Similar to Yoo et al. [19], our results suggest three phases of evolution that ultimately determine the expression levels of duplicated genes in the cotton genome.

The first phase consists of independent changes in upstream, cis-acting regulatory regions of genes prior to genome hybridization. In cotton, speciation of the two diploid genomes followed distinct evolutionary trajectories as evidenced by their differential accumulation of retrotransposons [51]. During speciation, the cis-acting promoter regions of protein coding genes also likely changed for a modest number of genes. Evidence of changes to cis-acting regulatory regions was observed by the conservation of homoeologous gene expression bias. If the observed expression biases were the result of a stochastic process during polyploid formation, then the direction of homoeologous expression bias would also be stochastic. When we inspected all genes with an expression bias in more than one accession (Figure 3A), we found that direction of bias was nearly always conserved in the four different accessions and in two different hybridization events (e.g. Figure 3B). Thus, the direction of expression bias of these loci may have been due to differential cis-acting regulation efficiency that evolved in the diploids and was subsequently conserved or maintained in the polyploid nucleus. This manner and level of conserved cis-acting regulation has not been previously reported. Previously, a mode of gene regulation (i.e. cis-) could only be ascribed to the small number of genes where the polyploid expression patterns were different that the diploids (Table 5).

Alternatively, or in addition, to cis-acting modification, transposable elements could have region of influence causing a quantitative reduction of transcription factor binding and correspondingly a reduction of transcription initiation [52]. Indeed, TEs have been differentially amplified and inserted in the A- and D-genomes [53]. A correlation of gene distance to the nearest TE in the D-genome reference sequence was only significant in one of the five datasets we tested. Thus, there was not a strong association between TE distance and expression bias, even with a $\sim 2 \times$ difference in genome size between the A- and D-genomes largely due to TE amplification and re-insertion. While a significant difference between categories of genes (A-biased or D-biased) was not apparent, only the distances from a single annotated reference genome were used (D-genome). We anticipate that a more meaningful comparison will be possible once the A-genome sequence has been published. A publically accessible A-genome sequence would allow the actual distances between A-genome TE insertions and annotated genes to be used with the current $\mathrm{D}$-genome distances for a more biologically meaningful comparison.

The second phase of duplicate gene evolution is hybridization. When two genomes are combined into a single nucleus, they share gene regulatory factors, which can lead to novel regulatory processes and changes in regulatory networks. These novel interactions have been considered as a genome shock that accompanies polyploidization and may provide a new source of genetic variation [29], see [45] for recent review. However, we found that most homoeologous genes were not expressed at statistically different levels in petals from tetraploids. If trans-acting factors were regulating homoeologous gene expression, both homoeologous loci would be expressed at similar or equal levels (e.g. Table 5). Our results suggest that either the expression levels of most genes are controlled to some degree by trans-acting factors or that our experimental design lacked sufficient power to detect a significant difference between homoeologous expression levels. With only three replicates, we had modest empirical estimates of power in our dataset. While some real homoeologous differences remained undetected, the general interpretation of the relative amounts of cis- and trans-acting regulation will be evaluated against future studies. Previous reports of an overall genome bias $\left(D_{T}>A_{T}\right.$ composed of many genes with small differences) due to either accelerated evolution of one of the two genomes or a mechanism of epigenetic control of expression, did not agree with our current findings $[18,20]$. Perhaps, the previous use of DNA microarrays resulted in an ascertainment bias through probe construction.

The second phase of gene evolution can also be interpreted through the lens of expression level dominance $[4,18,27]$. Nucleolar dominance is one type of molecular interaction that occurs when two genomes merge to form a polyploid and it is mediated by the targeting of specific siRNAs [54,55]. Expression level dominance is a more generalized phenomenon (without a sequence-specific trigger) and it was found in the diploid $F_{1}$-hybrid and natural Gossypium allopolyploids in previous microarraybased and RNA-seq studies [18,19,27]. We did not detect a consistent pattern of expression level dominance in our analysis. Within the comparative categories of gene expression that identify expression level dominance, the polyploid expression levels more commonly matched or exceeded the diploid species with the greater level of expression, independent of whether that diploid had the A- or D-genome. This consistent polyploid 'high-level expression' appeared to be a general trend that could also be explained by cis-acting transcriptional regulators. For 
example, suppose that the A- or D-genome has a cisacting regulating sequence that is more efficient than the other genome's homoeologous sequence due to mutation during the first phase of evolution. When combined into a polyploid nucleus, a more efficient cisacting regulator would continue to induce one of the two homoeologous genes at the requisite level for expression in the polyploid nucleus just as it had in the diploid nucleus (i.e. polyploid expression was the same as the higher expressing diploid). The less common events where the polyploid had lower expression levels could be due to trans-acting transcription repressors where the active repressor of one genome reduces expression levels in both genomes.

In the second evolutionary phase, we can also consider the constitution of the polyploid expression levels in the categories that match or exceed the expression levels of the diploids because we can distinguish between $\mathrm{A}_{\mathrm{T}}$ and $\mathrm{D}_{\mathrm{T}}$ transcripts. For example, if the polyploid matched or exceeded the expression level of the A-genome (Category IV and VI), the polyploid transcripts would largely consist of $A_{T}$ transcripts and not $D_{T}$ transcripts. The reverse was true for categories II and V where the polyploid matched the expression level of the D-genome diploid. Furthermore, most (50-70\%) of the genes in the 'expression level dominance' categories actually showed no change in the $\mathrm{A}_{\mathrm{T}^{-}}$relative to the $\mathrm{A}$-genome and in $\mathrm{D}_{\mathrm{T}^{-}}$relative to D-genome suggesting similar controls of expression between the diploid and the respective polyploid.

The third phase of gene expression evolution occurs between hybridization and adaptation to the species current biological niche. We found a larger number of biased homoeologous genes in the natural polyploids when compared to the diploid $F_{1}$-hybrid in agreement with Flagel et al. [18]. Since we had relatively similar amounts of statistical power for each accession, the increased number of genes detected with a homoeologous bias could have evolved since formation of the ancestral polyploid. When a significant bias was detected between the homoeologs, the difference was greater in the $\mathrm{D}_{\mathrm{T}}$ genomes of the natural polyploids than it was in the genome of the diploid $F_{1}$-hybrid (but not the $A_{T}$ biased genes). Perhaps, this observation represents a higher rate of mutation accumulation in the $\mathrm{A}_{\mathrm{T}}$-genome cis-acting regulatory regions than the homoeologous $\mathrm{D}_{\mathrm{T}^{-}}$-genome regions. It also agreed with our previous finding of general nucleotide diversity between the two genomes [36], our general findings of overall expression in Table 4, and previous reports [19]. Although rate heterogeneity seems unlikely, a relative rate test cannot be evaluated without the genome sequence of an appropriate outgroup (e.g. G. kirkii).

Here we used RNA-seq to characterize gene expression in polyploid cotton petals with an unprecedented level of resolution within each genome. Future comparisons of these findings to similar results in other polyploids will perhaps enable an extrapolation of general trends to unifying concepts of polyploid gene expression in plants. Collectively, these results suggest that after polyploidization 1) most homoeologous gene pairs are expressed at approximately equal amounts, 2) 20\% of expressed genes have biased expression, 3) a portion of these genes have expression biases in more than one polyploid and the direction of their bias is largely conserved, 4) for any set of genes with expression biases in more than one accession, only a very a small number of genes have a direction of expression bias that was unique or contrary to the observed direction in other accessions, and 5) that general trends of gene expression can be interpreted as cis- and trans-acting regulation of polyploid gene expression. We recognize that the simple explanations of increased and decreased levels of expression genes represent only a few of many possible combinations of cis- and trans-acting factors on gene expression within discrete and interconnected biochemical pathways. Indeed, the modest number of changes to polyploid gene expression corresponded to the limited number of genomic changes that were previously found to accompany polyploidization in cotton [56]. Perhaps, these exceptional gene expression biases indicated an additional level of gene expression regulation such as DNA methylation. The interesting exceptions to a conserved direction of gene expression bias and their potential effects on the phenotype merit further investigation.

\section{Additional files}

Additional file 1: Figure S1. Distribution of gene ontology (GO) terms in 11,469 commonly expressed petal genes. a) Biological process; b) Cellular component; and c) Molecular function.

Additional file 2: Figure S2. The enzymatic pathways can be divided into four general KEGG pathways: Metabolic pathways, Biosynthetic pathways, Degradation pathways and signaling pathways.

Additional file 3: Figure S3. Differences in log base 2 RPKM between the $A_{T}$ and $D_{T}$ genomes of each cotton species. Each histogram shows the number of genes (of the 11,469 commonly expressed petal genes) with each magnitude of homoeologous bias for Maxxa, G. tomentosum, the $F_{1}$ diploid hybrid, or $T \times 2094$. Positive values indicate an At bias, while negative values indicate a Dt bias.

Additional file 4: Figure S4. Counts of duplicated genes from this RNA seq study were placed into the 12 expression levels categories (identical to Figure 6), but here we have included the numbers from previously reported microarray results of petal transcriptomes [18] for comparison.

\section{Authors' contributions}

AR handled the plant material, prepared the libraries for sequencing, and helped write the manuscript. JTP performed the computational and statistical analyses and helped write the manuscript. JAU performed additional summaries of the results and wrote the manuscript. All authors read and approved the final manuscript.

\section{Acknowledgements}

We are grateful to the assistance of Kara Grupp at lowa State University for her help collecting petal tissue. The DNA sequencing was accomplished with the assistance of Brian Dalley at the Hustmant Cancer Center. The 
bioinformatic analysis was only possible through the generous support of the Fulton SuperComputer Laboratory at Brigham Young University. We acknowledge the support of the National Science Foundation Plant Genome Research Program and the support of Cotton Inc., Cary, NC.

Received: 31 July 2013 Accepted: 8 October 2013 Published: 6 January 2014

\section{References}

1. Wendel JF, Cronn RC: Polyploidy and the evolutionary history of cotton. In Advances in Agronomy. Volume 78. Edited by Sparks D. Newark, NJ, USA: Academic; 2003:139-186.

2. Krapovickas A, Seijo G: Gossypium ekmanianum (Malvaceae), algodon silvestre de la Republica Dominicana. Bonplandia 2008, 17:55-63.

3. Grover CE, Grupp KK, Wanzek RJ, Wendel JF: Assessing the monophyly of polyploid Gossypium species. Plant Syst Evol 2012, 298:1177-1183.

4. Grover CE, Gallagher JP, Szadkowski EP, Yoo MJ, Flagel LE, Wendel JF: Homoeolog expression bias and expression level dominance in allopolyploids. Plant J 2012, 196:966-971.

5. Salmon A, Flagel L, Ying B, Udall JA, Wendel JF: Homoeologous nonreciprocal recombination in polyploid cotton. New Phytol 2010, 186:123-134.

6. Chelaifa H, Monnier A, Ainouche M: Transcriptomic changes following recent natural hybridization and allopolyploidy in the salt marsh species Spartina $\times$ townsendii and Spartina anglica (Poaceae). New Phytol 2010, 186:161-174.

7. Qi B, Huang W, Zhu B, Zhong X, Guo J, Zhao N, Xu C, Zhang H, Pang J, Han F, Liu B: Global transgenerational gene expression dynamics in two newly synthesized allohexaploid wheat (Triticum aestivum) lines. BMC Biol 2012, 10:3. 2010 8:139.

8. Adams KL, Cronn R, Percifield R, Wendel JF: Genes duplicated by polyploidy show unequal contributions to the transcriptome and organ-specific reciprocal silencing. Proc Natl Acad Sci U S A 2003, 100:4649-4654

9. Udall JA: A novel approach for characterizing expression levels of genes duplicated by polyploidy. Genetics 2006, 173:1823-1827.

10. Hovav R, Udall JA, Hovav E, Rapp R, Flagel L, Wendel JF: A majority of cotton genes are expressed in single-celled fiber. Planta 2007, 227:319-329.

11. Rapp RA, Haigler CH, Flagel L, Hovav RH, Udall JA, Wendel JF: Gene expression in developing fibres of Upland cotton (Gossypium hirsutum L.) was massively altered by domestication. BMC Biol 2010, 8:139.

12. Hovav R, Chaudhary B, Udall JA, Flagel L, Wendel JF: Parallel domestication, convergent evolution and duplicated gene recruitment in allopolyploid cotton. Genetics 2008, 179:1725-1733.

13. Flagel LE, Wendel JF: Gene duplication and evolutionary novelty in plants. New Phytol 2009, 183:557-564.

14. Dong S, Adams KL: Differential contributions to the transcriptome of duplicated genes in response to abiotic stresses in natural and synthetic polyploids. New Phytol 2011, 190:1045-1057.

15. Degner JF, Marioni JC, Pai AA, Pickrell JK, Nkadori E, Gilad Y, Pritchard JK: Effect of read-mapping biases on detecting allele-specific expression from RNA-sequencing data. Bioinformatics 2009, 25:3207-3212.

16. McDaniell R, Lee BK, Song L, Liu Z, Boyle AP, Erdos MR, Scott LJ, Morken MA, Kucera KS, Battenhouse A, Keefe D, Collins FS, Willard HF, Lieb JD, Furey TS, Crawford GE, lyer VR, Birney E: Heritable individual-specific and allele-specific chromatin signatures in humans. Science 2010, 328:235-239.

17. Heap GA, Yang JH, Downes K, Healy BC, Hunt KA, Bockett N, Franke L, Dubois PC, Mein CA, Dobson RJ, Albert TJ, Rodesch MJ, Clayton DG, Todd JA, Van Heel DA, Plagnol V: Genome-wide analysis of allelic expression imbalance in human primary cells by high-throughput transcriptome resequencing. Hum Mol Genet 2010, 19:122-134.

18. Flagel LE, Wendel JF: Evolutionary rate variation, genomic dominance and duplicate gene expression evolution during allotetraploid cotton speciation. New Phytol 2010, 186:184-193.

19. Yoo MJ, Szadkowski E, Wendel JF: Homoeolog expression bias and expression level dominance in allopolyploid cotton. Heredity 2013 110:171-180.
20. Flagel L, Udall J, Nettleton D, Wendel JF: Duplicate gene expression in allopolyploid Gossypium reveals two temporally distinct phases of expression evolution. BMC Biol 2008, 6:16. 2010 8:139.

21. Bottley A, Xia GM, Koebner RMD: Homoeologous gene silencing in hexaploid wheat. Plant J 2006, 47:897-906.

22. Buggs RJA, Chamala S, Wu W, Gao L, May GD, Schnable PS, Soltis DE, Soltis PS, Barbazuk WB: Characterization of duplicate gene evolution in the recent natural allopolyploidTragopogon miscellusby next-generation sequencing and Sequenom iPLEX MassARRAY genotyping. Mol Ecol 2010, 19:132-146.

23. Koh J, Soltis PS, Soltis DE: Homeolog loss and expression changes in natural populations of the recently and repeatedly formed allotetraploid Tragopogon mirus (Asteraceae). BMC Genomics 2010, 11:97.

24. Wang J, Tian L, Madlung A, Lee H-S, Chen M, Lee JJ, Watson B, Kagochi T, Comai L, Chen ZJ: Stochastic and epigenetic changes of gene expression in Arabidopsis polyploids. Genetics 2004, 167:1961-1973.

25. Gaeta RT, Pires JC, Iniguez-Luy F, Leon E, Osborn TC: Genomic changes in resynthesized brassica napus and their effect on gene expression and phenotype. Plant Cell 2007, 19:3043-3417.

26. Auger DL, Sheridan WF: Plant Chromosomal Deletions, Insertions, and Rearrangements. In Plant Cytogenetics. Edited by Bass HW, Birchler JA. New York: Springer; 2011:3-36.

27. Rapp RA, Udall JA, Wendel JF: Genomic expression dominance in allopolyploids. BMC Biol 2009, 7:18. 2010 8:139.

28. Bardil A, De Almeida JD, Combes MC, Lashermes P, Bertrand B: Genomic expression dominance in the natural allopolyploid Coffea arabica is massively affected by growth temperature. New Phytol 2011, 192:760-774.

29. Osborn TC, Chris Pires J, Birchler JA, Auger DL, Jeffery Chen Z, Lee H-S, Comai L, Madlung A, Doerge RW, Colot V, Martienssen RA: Understanding mechanisms of novel gene expression in polyploids. Trends Genet 2003, 19:141-147.

30. Costa V, Angelini C, De Feis I, Ciccodicola A: Uncovering the complexity of transcriptomes with RNA-Seq. J Biomed Biotechnol 2010, 2010:853916.

31. Wang Z, Gerstein M, Snyder M: RNA-Seq: a revolutionary tool for transcriptomics. Nat Rev Genet 2009, 10:57-63.

32. Wan CY, Wilkins TA: A modified hot borate method significantly enhances the yield of high-quality RNA from cotton ( gossypium hirsutum L.). Anal Biochem 1994, 223:7-12.

33. Wu TD, Nacu S: Fast and SNP-tolerant detection of complex variants and splicing in short reads. Bioinformatics 2010, 26:873-881.

34. Paterson AH, Wendel JF, Gundlach H, Guo H, Jenkins J, Jin D, Llewellyn D, Showmaker KC, Shu S, Udall J, Yoo M-J, Byers R, Chen W, Doron-Faigenboim A, Duke MV, Gong L, Grimwood J, Grover C, Grupp K, Hu G, Lee T-H, Li J, Lin L, Liu T, Marler BS, Page JT, Roberts AW, Romanel E, Sanders WS, Szadkowski E, et al: Repeated polyploidization of Gossypium genomes and the evolution of spinnable cotton fibres. Nature 2012, 492:423-427.

35. Page JT, Gingle AR, Udall JA: PolyCat: a resource for genome categorization of sequencing reads from allopolyploid organisms. G3: Genes|Genomes|Genetics 2013, 3:517-525.

36. Page JT, Huynh MD, Liechty ZS, Grupp K, Stelly DM, Hulse AM, Ashrafi H, Van Deynze A, Wendel JF, Udall JA: Insights into the evolution of cotton diploids and polyploids from whole-genome re-sequencing. G3: Genes| Genomes|Genetics 2013, 3:1809-1818.

37. Piccolo SR, Sun Y, Campbell JD, Lenburg ME, Bild AH, Johnson WE: A single-sample microarray normalization method to facilitate personalized-medicine workflows. Genomics 2012, 100:337-344.

38. Conesa A, Götz S, García-Gómez JM, Terol J, Talón M, Robles M: Blast2GO: a universal tool for annotation, visualization and analysis in functional genomics research. Bioinformatics 2005, 21:3674-3676

39. Kanehisa M, Goto S, Sato Y, Furumichi M, Tanabe M: KEGG for integration and interpretation of large-scale molecular data sets. Nucleic Acids Res 2011, 40:D109-D114.

40. Robinson MD, McCarthy DJ, Smyth GK: EdgeR: a bioconductor package for differential expression analysis of digital gene expression data. Bioinformatics 2010, 26:139-140.

41. Flagel LE, Wendel JF, Udall JA: Duplicate gene evolution, homoeologous recombination, and transcriptome characterization in allopolyploid cotton. BMC Genomics 2012, 13:1-1.

42. Tanase K, Nishitani C, Hirakawa H, Isobe S, Tabata S, Ohmiya A, Onozaki T: Transcriptome analysis of carnation (Dianthus caryophyllus L.) based on next-generation sequencing technology. BMC Genomics 2012, 13:292. 
43. Li H, Dong Y, Yang J, Liu X, Wang Y, Yao N, Guan L, Wang N, Wu J, Li X: De novo transcriptome of safflower and the identification of putative genes for oleosin and the biosynthesis of flavonoids. PLOS ONE 2012, 7:e30987.

44. Senchina DS, Alverez I, Cronn RC, Liu B, Rong J, Noyes RD, Paterson AH, Wing RA, Wilkins TA, Wendel JF: Rate variation among nuclear genes and the age of polyploidy in gossypium. Mol Biol Evol 2003, 20:633-643.

45. Madlung A, Wendel JF: Genetic and epigenetic aspects of polyploid evolution in plants. Cytogenet Genome Res 2013, 140:270-285.

46. Udall JA: A global assembly of cotton ESTs. Genome Res 2006, 16:441-450.

47. Studer A, Zhao Q, Ross-Ibarra J, Doebley J: Identification of a functional transposon insertion in the maize domestication gene tb1. Nat Publ Group 2011, 43:1160-1163.

48. Hovav R, Udall JA, Chaudhary B, Hovav E, Flagel L, Hu G, Wendel JF: The evolution of spinnable cotton fiber entailed prolonged development and a novel metabolism. PLoS Genet 2008, 4:e25.

49. Betancur L, Singh B, Rapp RA, Wendel JF, Marks MD, Roberts AW, Haigler CH: Phylogenetically distinct cellulose synthase genes support secondary wall thickening in arabidopsis shoot trichomes and cotton fiber. I Integr Plant Biol 2010, 52:205-220.

50. Muhlemann JK, Maeda H, Chang CY, San Miguel P, Baxter I, Cooper B, Perera MA, Nikolau BJ, Vitek O, Morgan JA: Developmental changes in the metabolic network of snapdragon flowers. PLOS ONE 2012, 7:e40381.

51. Hawkins JS, Kim H, Nason JD, Wing RA, Wendel JF: Differential lineagespecific amplification of transposable elements is responsible for genome size variation in Gossypium. Genome Res 2006, 16:1252-1261.

52. Freeling M, Woodhouse MR, Subramaniam S: Fractionation mutagenesis and similar consequences of mechanisms removing dispensable or less-expressed DNA in plants. Curr Opin Plant Biology 2012, 15:131-139.

53. Hawkins JS, Proulx SR, Rapp RA, Wendel JF: Rapid DNA loss as a counterbalance to genome expansion through retrotransposon proliferation in plants. Proc Natl Acad Sci U S A 2009, 106:17811-17816.

54. Tucker S, Vitins A, Pikaard CS: Nucleolar dominance and ribosomal RNA gene silencing. Curr Opin Cell Biol 2010, 22:351-356.

55. Preuss SB, Costa-Nunes P, Tucker S, Pontes O, Lawrence RJ, Mosher R, Kasschau KD, Carrington JC, Baulcombe DC, Viegas W, Pikaard CS: Multimegabase silencing in nucleolar dominance involves siRNAdirected DNA methylation and specific methylcytosine-binding proteins. Mol Cell 2008, 32:673-684.

56. Liu B, Brubaker CL, Mergeai G, Cronn RC, Wendel JF: Polyploid formation in cotton is not accompanied by rapid genomic changes. 2001, 44:321-330.

doi:10.1186/1471-2229-14-3

Cite this article as: Rambani et al.: Polyploidy and the petal

transcriptome of Gossypium. BMC Plant Biology 2014 14:3.

\section{Submit your next manuscript to BioMed Central and take full advantage of:}

- Convenient online submission

- Thorough peer review

- No space constraints or color figure charges

- Immediate publication on acceptance

- Inclusion in PubMed, CAS, Scopus and Google Scholar

- Research which is freely available for redistribution 